\title{
Образовательная миграция в регионах ресурсного типа
}

\author{
М.В. КУРБАТОВА*, И.В. ДОНОВА**, Е.А. КРАНЗЕЕВА***, М.Г. ЛЕУХОВА****
}

*Маргарита Владимировна Курбатова - доктор экономических наук, главный научный сотрудник научно-учебной лаборатории экономики природных ресурсов и окружающей среды ФГАОУ ВО «Сибирский федеральный университет», Красноярск, Россия, kurbatova-07@mail.ru, https://orcid.org/0000-0002-7017-5266

**Инна Вениаминовна Донова - кандидат экономических наук, доцент кафедры менеджмента им. И.П. Поварича, ФГБОУ ВО «Кемеровский государственный университет», Кемерово, Россия, idonova@gmail.com, https://orcid.org/0000-0001-9370-5402

***Елена Анатольевна Кранзеева - кандидат социологических наук, заведующий кафедрой социологических наук, ФГБОУ ВО «Кемеровский государственный университет», Кемерово, Россия, elkranzeeva@mail.ru, https:/orcid.org/0000-0003-2577-9017

****Мария Геннадьевна Леухова - кандидат исторических наук, доцент кафедры истории России, ФГБОУ ВО «Кемеровский государственный университет», Кемерово, Россия, leukhova@kemsu.ru, https://orcid.org/0000-0002-5891-2737

Цитирование: Курбатова М.В., Донова И.В., Кранзеева Е.А., Леухова М.Г. (2022) Образовательная миграция в регионах ресурсного типа // Мир России. Т. 31. № 1. С. 91-112. DOI: 10.17323/1811-038X-2022-31-1-91-112

\section{Аннотация}

В статье рассматривается образовательная миграџия в регионах ресурсного типа при переходе «школа - вуз»; выделены и охарактеризованы ее структурные и субъектные факторы. Важснейшим структурным фактором образовательной миграции являются ресурсно-отраслевые характеристики регионов, особенности их рынков труда. Показано, что потоки общей и образовательной миграции из регионов ресурсного типа выше, чем в среднем по регионам и по нересурсным регионам. Это сопровождается ухудшаюшим отбором человеческого капитала, оттоком выпускников с более высокими образовательными результатами и социально-экономическим статусом семей. Данные регионы в экономике России становятся поставщиками не только природных и финансовых ресурсов, но и человеческого капитала, наблюдается «западный дрейф» образовательной миграчии, усиливающий общий мигращионный поток в западном направлении. Другим структурным фактором формирования потоков образовательной миграџии является институциональ-

Исследование выполнено при финансовой поддержке РФФИ в рамках научного проекта 19-010-00244 «Институциональная организация рынка труда в регионах ресурсного типа».

Статья опубликована в рамках проекта НИУ ВШЭ по поддержке публикаций авторов российских образовательных и научных организаций «Университетское партнерство».

Статья поступила в редакцию в июне 2021 г. 
ный дизайн системы высшего образования, сложившийся в результате реформ, направленных на повышение ее отраслевой эффективности. Соответствующие институциональные новации (введение ЕГЭ, новых механизмов выделения контрольных ицфр приема, показателей оченки эффективности деятельности вузов) в целом ухудиили положение систем высшего образования регионов ресурсного типа, прежде всего по характеристикам доступности. Исключения наблюдаются в традиционных университетских центрах (Томск, Казань, Самара). В иелом сформированная сеть вузов и распределение контрольных ичифр приема определили отток человеческого капитала из регионов ресурсного типа.

В статье дана характеристика формирования новых миграционных стратегий домохозяйств, при которых переход «школа - вуз» рассматривается как «судьбоносный момент», к которому готовятся заранее, а окончание школь становится толчком для миграции всей семьи (одновременной или растянутой во времени). Более подробно структурные факторы образовательной миграции описаны на примере Кемеровской области - Кузбасса. Приведены данные об оттоке из области стобалльников и результаты глубинного интервью с родителями выпускников одного из образцовых образовательных учреждений Кузбасса. Выявлено, что образовательная миграџия при переходе «школа - вуз»- семейное решение не только потому, что опирается на личные предпочтения, интеллектуальные возможности ребенка и ресурсы семей, но и потому, что основывается на долгосрочных семейных планах, связанных с мобильностью (территориальной, профессиональной). Таким образом, происходит отток не только выпускников школ, но и их семей. Регион теряет и потенциальных специиалистов, и действующих высококвалифицированных работников, и предпринимателей. Показано, что наблюдаемые в регионах ресурсного типа процессы образовательной миграции при переходе «школа - вуз» могут иметь долговременные последствия, связанные с формированием кумулятивной связи образовательной миграции и регионального развития. Это требует изменений в проводимой сочиальной-экономической и образовательной политике как на федеральном, так и на региональном уровнях.

Ключевые слова: образовательная миграция, регионы ресурсного типа, рынки труда, высшее образование, региональное развитие, миграџионные стратегии домохозяйств

Важнейшей проблемой социально-экономического развития России является фрагментация экономического и социального пространства, когда углубляются межрегиональные разрывы, социально-экономическая система страны оказывается совокупностью регионов, экономики которых слабо связаны друг с другом цепочками создания стоимости, а условия и качество жизни населения все более дифференцируются. Будущее регионов и их место в российской экономике зависят как от объемов инвестиций в человеческий капитал, так и от направленности миграционных потоков, прежде всего образовательной. Дело в том, что инвестиции регионов в человеческий капитал вследствие образовательной миграции далеко не всегда окупаются; отток либо приток выпускников зависит от характеристик регионов и состояния их рынков труда.

Российские регионы существенно различаются между собой по ресурсно-отраслевым характеристикам: так, регионы ресурсного типа являются основными экспортерами, обеспечивают пополнение федерального бюджета, а также формируют платежеспособный спрос на продукцию других секторов экономики. Эти же регионы чаще всего оказываются на периферии процесса современных технологических изменений и социальной трансформации общества, что обусловливает 
отток человеческого капитала, сокращение потенциала их дальнейшего развития и еще большую фрагментацию экономического и социального пространства страны.

Цель статьи - дать характеристику образовательной миграции при переходе «школа - вуз» в регионах ресурсного типа и определить влияние на нее структурных и субъектных факторов.

Гипотеза исследования: поток образовательной миграции из регионов ресурсного типа выше, чем в среднем по регионам, что сопровождается ухудшающим отбором человеческого капитала. Этот поток формируется под влиянием ресурсно-отраслевых характеристик данных регионов, а также сложившегося институционального дизайна российской системы высшего образования, которые определяют решения домохозяйств о миграции.

Эмпирической базой исследования являются статистические данные Федеральной службы государственной статистики (Росстата), Территориального органа Федеральной службы государственной статистики по Кемеровской области - Кузбассу (Кемеровостата) и материалы глубинного интервью с родителями выпускников образовательного учреждения Кузбасса.

\section{Образовательная миграция: структурные и субъектные факторы}

Образовательная и послеобразовательная миграция интересны современным исследователям разных отраслей науки: в демографических исследованиях обращается внимание на формирование миграционных потоков [Варшавская, Чудиновских 2014]; в менеджменте - на миграционные намерения, причины миграции и практики управления, способствующие удержанию кадров [Шагалкина u дp. 2019]; в экономике образования образовательная миграция обычно рассматривается в контекстах формирования образовательных траекторий либо неоднородности образовательного пространства [Кашницкий и др. 2016; Захаров, Адамович 2020]. В социологии большое внимание уделяется выбору образовательных траекторий разными социальными группами населения в условиях ресурсных различий семей и ограничений локальных рынков труда [Бессуднов и др. 2017; Хавенсон, Чиркина 2018; Константиновский, Попова 2015]. Центральными становятся вопросы накопления человеческого капитала, преодоления неравенства, основных механизмов социальной мобильности. В последнее время фокус исследований смещается к проблемам поведения в сфере образования и роли рынка труда в формировании миграционных намерений молодежи. Во многих работах поднимается проблема взаимовлияния образовательной миграции и накопления человеческого капитала на определенных территориях [Габдрахманов, Никифорова, Лешуков 2019; Габдрахманов 2019]. С одной стороны, уровень социальноэкономического развития регионов во многом определяет объем инвестиций в человеческий капитал и влияет на миграционные намерения молодежи при переходе «школа - вуз», с другой - масштабы и направленность потока образовательной миграции становятся важнейшим фактором развития.

В экономике образования, основанной на предпосылке, что наиболее эффективным механизмом распределения ресурсов является рынок, считается, что если региональный рынок труда способен предоставить привлекательные рабочие 
места и мотивирует возвратное движение, то потоки образовательной миграции не создают для регионов рисков оттока молодежи, а ее межрегиональная миграция рассматривается с позиций эффективности распределения ресурсов по вузам. Предполагается наличие многополосной магистрали, по которой по встречным маршрутам движутся абитуриенты и выпускники, обеспечивая достижение аллокативной эффективности подготовки кадров в системе высшего образования, и в современной России решения по образовательной политике принимаются на основе подобных постулатов. Однако идеалистические представления о рыночных механизмах в реальной экономике не реализуется даже на рынках простейших товаров и услуг. Более того, в образовании они не срабатывают как по причине особых свойств производимых услуг (социально значимые, доверительные блага), так и вследствие укорененности миграционного поведения молодежи в социальных структурах. Влияние на формирование миграционного потока не ограничивается текущим состоянием региональных экономик и их рынков труда, а также состоянием региональных образовательных систем, характеризующихся пространственной неоднородностью и предоставляющих различные образовательные возможности. В не меньшей степени они определяются социокультурными факторами, различиями в качестве жизни, в «социальных лифтах» и прочих.

В современном обществе, по мнению Ж. Пакульски и М. Вотерс, социокультурные различия проявляются в выборе стилей жизни [Pakulski, Waters 1996]. П. ДиМаджио видит неравенство в том, как учащиеся из разных семей с различным культурным капиталом осваивают общественные ресурсы, а его причины связывает с влиянием культуры, ее способностью фиксировать социальные позиции, определять траекторию мобильности на тот уровень, который соответствует личностным ресурсам индивида [DiMaggio 1982]. Теория индивидуализации не отрицает роль экономических и социальных структур в мобильности, но пересматривает соотношение ее субъектных и структурных факторов [Черныш, Епихина 2018]. В этой связи важным вопросом исследования образовательной миграции становится сопряжение субъектных факторов с возможностями и ограничениями структурных характеристик развития регионов и их региональных систем высшего образования.

В экономической литературе взаимное влияние образовательной миграции и регионального развития исследуется с точки зрения воздействия качества образования на принятие выпускниками школ решений о выборе вуза и впоследствии о трудоустройстве. На примере Великобритании приводятся доводы в пользу большего влияния на экономику региона послеобразовательной миграции выпускников, нежели входящих потоков абитуриентов [Faggian 2006]. Данные итальянских исследований, напротив, свидетельствуют о доминирующем влиянии на накопленный человеческий капитал региона решений, принятых в момент выбора университета, т. к. подавляющее большинство итальянских студентов после окончания обучения склонны оставаться и работать там, где они завершили свое образование [Ciriaci 2014]. Финские исследователи обращают внимание на то, что миграция намного выше среди выпускников периферийных университетов, чем в центрах роста (в частности в Хельсинки), и тех, кто учится за пределами своего региона [Haapanen, Tervo 2011]. Проверяются предположения о том, что последующая миграция связана с предыдущей, а также гипотеза Сьястада-Беккера о том, что люди с более высоким человеческим капиталом более географически мобильны [Sjaastad 1962]. 
Качество образования в конкретном университете влияет не только на решения выпускников школ о выборе вуза, но и повышает привлекательность региона, а удержание выпускников на местном рынке труда является многообещающим путем решения его экономических проблем [Abel, Deitz 2011]. Политико-экономическое значение данного факта заключается в том, что «человеческий капитал может накапливаться только в более богатых регионах, где региональная отдача от образовательной политики будет увеличиваться еще больше, а остальная часть страны будет отставать» [Ciriaci 2014, p. 1596]. Если между регионами не происходит крупных финансовых трансфертов, значительный чистый отток человеческого капитала объясняется меньшими государственными инвестициями в высшее образование в регионах, где наблюдается чистый отток выпускников [Faggian, MacCann 2009]. В литературе обсуждается наличие не столько прямой, сколько кумулятивной связи между региональным развитием и притоком студентов.

На фоне нарастающего регионального неравенства образовательная миграция становится одним из важных аспектов социальной мобильности. Население стремится покинуть регионы с низким уровнем доходов и отсутствием перспектив развития и переместиться в регионы с более благоприятными условиями жизни. В литературе повышение уровня мобильности рассматривается как часть проекта современности в контексте дискурсов как современности, так и неолиберализма [Christie 2007, p. 2445]. Однако решение уехать учиться в другой регион оказывается не индивидуальным, а совместным выбором, при этом семья учитывает не только интеллектуальные возможности и амбиции ребенка, но и свои совокупные финансовые ресурсы, включенность в социальные сети. Исследуя истории взросления молодых людей в Великобритании, Ж. Холланд и Р. Томсон используют понятие судьбоносного момента, что помогает выявить «конфигурацию структурных обстоятельств, индивидуальных действий, временных рамок и случайностей» [Holland, Thomson 2009, p. 451] при переходе к зрелости. Показано, что готовность родителей «незамедлительно, решительно и с толком» [Holland, Thomson 2009, p. 459] направить ресурсы на защиту ребенка в критической ситуации приводит к благоприятному результату. В свою очередь, К. Эванс заключает, что современной молодежи присущи готовность к действию и вера в способность управлять собственной жизнью, невзирая на положение на рынке труда и социальное происхождение. При этом оптимизм и вера состоят в том, что залогом успеха являются собственный труд, знания, квалификация и опыт, сопровождаются высокой степенью понимания структурных ограничений и осознанием того, что личные усилия «не всегда решают все» [Evans 2002, p. 259].

Таким образом, в современной экономической и социологической литературе выделяются структурные факторы формирования потоков образовательной миграции: (1) социально-экономические характеристики регионов, определяющие их привлекательность для молодежи, возвратную миграцию, способность к удержанию выпускников на местном рынке труда; (2) состояние региональных систем высшего образования, различающихся по объему и качеству предложения образовательных услуг. При этом выбор в пользу образовательной миграции оказывается решением смены стиля жизни, перехода к более современным и динамичным ее условиям. Значимыми субъектными факторами становятся планы и финансовые ресурсы семей, личные предпочтения, интеллектуальные возможности и амбиции, включенность в социальные сети и т. п. 


\section{Образовательная миграция: ведомственный подход и интересы развития регионов}

Современный институциональный дизайн российской системы высшего образования является результатом сначала ее приспособления к процессам рыночной трансформации, а затем - институционального проекта российской бюрократии [Курбатова и др. 2020]. В 2000-х гг. ее развитие стало осуществляться на основе формирования квазирыночных механизмов, а целью проектов реформирования явилось повышение отраслевой эффективности. Преобразования зашли настолько далеко, что стали оказывать серьезное воздействие на накопление человеческого капитала и образовательную мобильность молодежи в регионах, однако при этом так и не были сформированы адекватные новым условиям механизмы согласования индивидуальных решений о накоплении человеческого капитала и образовательной миграции с потребностями социально-экономического развития регионов. В советский период данное согласование обеспечивалось:

- во-первых, жестким отбором при поступлении в вузы, целевым направлением на продолжение обучения в центральные вузы, централизованным распределением выпускников, при этом образовательная и послеобразовательная миграция встраивались в систему централизованного планирования;

- во-вторых, созданием и развитием сети региональных вузов, ориентированных на подготовку кадров для регионов и компенсирующим «сбои в системе централизованного распределения рабочей силы» [Кузьминов и др. 2013, c. 25-26]. Формирование новых вузов обеспечивалось серьезным организационным сопровождением со стороны партийных и советских органов, привлечением кадров преподавателей из разных регионов страны [Коновалов и др. 2019], причем выпускники не только центральных, но и региональных вузов планово направлялись на работу в разные регионы;

- в-третьих, системой компенсации изменения места проживания, включающей выплаты «подъемных» при переезде, районные коэффициенты к заработной плате, более динамичное карьерное продвижение, лучшее снабжение определенных территорий в условиях товарного дефицита.

Несмотря на то, что с каждым послевоенным десятилетием плановое регулирование потока специалистов (по преимуществу «восточный дрейф») требовало все больших организационных и финансовых затрат, советская модель в целом обеспечивала необходимый для развития территорий поток человеческого капитала. Как замечают М.А. Лисюткин и И.Д. Фрумин, «в советское время предпринимались целенаправленные меры по выравниванию качества и обеспечению доступности высшего образования в региональном разрезе» [Лисюткин, Фрумин 2014, с. 18]. Проектируемая российская модель согласования индивидуальных решений о накоплении человеческого капитала и образовательной миграции с потребностями социально-экономического развития регионов предполагала, что новый институциональный дизайн обеспечит повышение отраслевой эффективности, а конкуренция регионов за ресурсы приведет к созданию механизмов привлечения и удержания человеческого капитала на территориях. На самом же деле он, скорее, разбалансировал потоки человеческого капитала с целями и задачами социально-экономического развития страны, способствуя оттоку человеческо- 
го капитала из целого ряда регионов [Лисюткин, Фрумин 2014; Захаров, Адамович 2020]. На формирование потоков образовательной миграции решающее воздействие оказали такие элементы институционального дизайна, как механизмы отбора абитуриентов и характер развития сети вузов.

Государственная образовательная политика РФ «реализуется по институциональному принципу», т. е. «объектом управления и развития являются отдельные вузы или вузовские сегменты» [Лешуков, Лисюткин 2015, с. 30], а развитие региональных образовательных систем попадает в зависимость от отбора ведущих вузов по программам превосходства и масштабов их финансирования. В результате «в то время, как ресурсная база одних вузов улучшается, у других она ухудшается» [Лисюткин 2017, с. 75], «с каждым циклом (реализации данной политики прим. aвm.) сужается группа университетов, которым государство на конкурсной основе оказывает поддержку» [Кузьминов и др. 2013, с. 54]. Таким образом, инициативы превосходства, обеспечивая концентрацию ресурсов в узкой группе привилегированных вузов, формируют условия, способствующие усилению пространственной неоднородности системы высшего образования как по ее доступности, так и по качеству. Все это стимулирует усиление оттока наиболее подготовленной молодежи из целого ряда регионов. Вследствие сосредоточения в центральных регионах страны статусных вузов, обеспечивающих более качественное высшее образование, наблюдается «западный дрейф» образовательной миграции, усиливающий общий миграционный поток.

Активизация образовательной миграции была обусловлена и введением нового механизма отбора (по баллам ЕГЭ) [Козлов и др. 2017]. Заложенная в проект ЕГЭ идея о расширении образовательных возможностей и «социальных лестницах» себя полностью не оправдала. Исследования формирования образовательных траекторий показывают, что академический трек и поступление в ведущие вузы выбирают преимущественно домохозяйства с более высоким социально-экономическим положением [Бессуднов и др. 2017]. «Фактически сложилась система двух разных высших образований: более и менее селективного, имеющего разную ценность для разных социальных слоев» [Хавенсон, Чиркина 2018, с. 78]. Этому служит и система распределения контрольных цифр приема (КЦП): «Распределение КЦП между вузами и регионами России формирует неравные условия для абитуриентов из разных уголков страны и с разным социально-экономическим статусом» [Габдрахманов, Лешуков, Платонова 2019, с. 33]. Соответственно формируется устойчивый поток более подготовленных абитуриентов из более благополучных семей в регионы базирования ведущих вузов страны. Другие регионы, инвестирующие в среднее образование, сталкиваются с утечками человеческого капитала. Эти регионы либо компании, расположенные на их территориях, впоследствии должны еще раз инвестировать в привлечение и удержание высококвалифицированных кадров уже при выходе выпускников вузов на рынок труда - таким образом формируется кумулятивная связь между притоком/оттоком студентов и региональным развитием.

Сложившаяся в России ситуация, когда аналогичные по размеру и уровню социально-экономического развития регионы кардинально отличаются количеством высших учебных заведений, численностью студентов и качеством их подготовки, является уникальной для мировой практики [Лешуков, Лисюткин 2015, с. 29]. Эти различия формируются проводимой политикой поддержки ведущих вузов и выживания прочих. Углубление разрыва между ними становится серьезной 
проблемой. В конце 2019 г. Счетная палата РФ по результатам проверки Ивановского и Владимирского государственных университетов сделала следующий вывод: «Эти вузы имеют ограниченные возможности для формирования такого человеческого капитала, который мог бы в будущем перезапустить региональную экономику» ${ }^{1}$. Ею зафиксированы недостаточный уровень финансирования, выделение Минобрнауки незначительных контрольных цифр приема по некоторым направлениям обучения вузов и резкое сокращение ассигнований из федерального бюджета на научные исследования. В докладе 2021 г. Счетная палата РФ, сделав вывод в целом о позитивном воздействии на развитие российской системы высшего образования Проекта 5-100, отметила: «Вузы, принимающие участие в Проекте $5-100,<\ldots>$ аккумулировали большую часть финансовых и кадровых ресурсов, привлекали наиболее перспективных студентов и исследователей, что усилило диспропорции внутри системы высшего образования в Российской Федерации» ${ }^{2}$.

Проблемы институциональных деформаций образовательной системы вышли на политический уровень: вопрос о развитии региональных вузов был поставлен в Послании Президента РФ Федеральному Собранию³. Для корректировки допущенных ведомственных «перегибов» потребовалось решение сверху: новой целью была провозглашена поддержка региональных вузов в интересах предотвращения концентрации высококвалифицированных кадров в крупных городах 4 .

\section{Регионы ресурсного типа как поставщики человеческого капитала}

Регионы ресурсного типа занимают особое место в российской экономике, их основу составляют экспортно-ориентированные отрасли добывающей промышленности, которые являются локомотивами развития и определяют место России в глобальном разделении труда. В данной статье используются результаты комплексной оценки ресурсной зависимости (по показателям доли добывающих отраслей в ВРП и соотношение долей добывающих и обрабатывающих отраслей в ВРП по данным 2016 г. по шкале от 0 до 10) [Курббатова и др. 2019]. Проведенные расчеты позволили выделить 27 регионов ресурсного типа, преимущественно расположенных на севере и востоке страны, которые, в свою очередь, были разделены на 4 группы, различающиеся степенью ресурсной зависимости: (1) 7 регионов очень высокого уровня ресурсной зависимости (Ненецкий автономный округ, Чукотский автономный округ, Республика Саха (Якутия), Ханты-Мансий-

\footnotetext{
1 Региональные вузы в современных условиях не выступают двигателями развития территорий (2020) // Счетная палата Российской Федерации. 10 января 2020 // http://www.ach.gov.ru/press_center/news/39754, дата обращения 15.10.2021.

2 Отчет о результатах экспертно-аналитического мероприятия «Анализ эффективности мер государственной поддержки российских университетов, направленных на повышение их конкурентоспособности среди ведущих мировых научно-образовательных центров». Утвержден Коллегией Счетной палаты Российской Федерации 2 февраля 2021 г. (2021) // Счетная плата Российской Федерации // https://ach.gov.ru/upload/iblock/ab8/ab8e9ce46a64ed39020ff200d407dde1.pdf, c. 3, дата обращения 15.10.2021.

3 Послание Президента РФ Федеральному Собранию (2020) // КонсультантПлюс. 15 января 2020 // http://www.consultant.ru/document/cons_doc_LAW_342959, дата обращения 15.10.2021.

4 Путин заявил, что власти РФ наращивают поддержку вузов в регионах (2021) // ТАСС. 17 февраля 2021 // https://tass.ru/obschestvo/10720463; Минобрнауки в ближайшие недели запустит программу по поддержке региональных вузов (2021) // ТАСС. 21 апреля 2021 // https://tass.ru/obschestvo/11208159, дата обращения 15.10.2021.
} 
ский автономный округ - Югра, Ямало-Ненецкий автономный округ, Магаданская и Сахалинская области); (2) 3 региона с преобладанием добывающих отраслей над обрабатывающими при средней доле добывающих отраслей в ВРП (Республика Тыва, Астраханская область, Амурская область); (3) 6 регионов высокого уровня ресурсной зависимости (Забайкальский край, Республика Коми, Томская область, Оренбургская область, Иркутская область, Кемеровская область); (4) 11 регионов среднего уровня ресурсной зависимости (Мурманская область, Республика Татарстан, Удмуртская Республика, Тюменская область (без автономных округов), Республика Хакасия, Камчатский край, Республика Карелия, Самарская область, Красноярский край, Пермский край, Белгородская область).

Регионы ресурсного типа отличаются от других регионов своим миграционным потоком, способным вызвать серьезные последствия. Межрегиональная миграция влияет на перераспределение человеческого капитала и в зависимости от состава мигрантов ведет к его накоплению или потере. Исследования возрастной структуры миграции показывают высокую долю молодежи во всех ее потоках, что и обеспечивает ее селективную роль. Так, по данным переписи 2010 г., доля населения в возрасте 15-29 лет составляла 22,8\%, во внутристрановых потоках мигрантов его удельный вес примерно в 2 раза выше, в международной миграции - почти в 1,5 раза. При этом пик миграции приходится на возраст 17-18 лет [Мкртчян 2014], что соответствует переходу «школа - вуз».

Таблица 1. Коэффициенты миграционного прироста (на 10 тыс. населения) по группам регионов за 2011-2019 гг.

\begin{tabular}{|l|c|c|c|c|c|c|c|c|c|}
\hline & $\mathbf{2 0 1 1}$ г. & $\mathbf{2 0 1 2}$ г. & $\mathbf{2 0 1 3}$ г. & $\mathbf{2 0 1 4}$ г. & $\mathbf{2 0 1 5}$ г. & $\mathbf{2 0 1 6}$ г. & $\mathbf{2 0 1 7}$ г. & $\mathbf{2 0 1 8}$ г. & $\mathbf{2 0 1 9}$ г. \\
\hline $\begin{array}{l}\text { Очень высокий уровень } \\
\text { ресурсной зависимости }\end{array}$ & 12,14 & $-42,57$ & $-76,29$ & $-62,71$ & $-75,57$ & $-45,86$ & $-50,14$ & $-45,43$ & 4,14 \\
\hline $\begin{array}{l}\text { Преобладание } \\
\text { добывающих отраслей над } \\
\text { обрабатывающими при } \\
\text { средней доле добывающих } \\
\text { отраслей в ВРП }\end{array}$ & $-53,33$ & $-69,33$ & $-60,33$ & $-23,97$ & $-57,20$ & $-33,47$ & $-26,33$ & $-35,67$ & $-29,93$ \\
\hline $\begin{array}{l}\text { Высокий уровень } \\
\text { ресурсной зависимости }\end{array}$ & $-31,67$ & $-39,50$ & $-44,50$ & $-39,83$ & $-38,67$ & $-34,00$ & $-46,67$ & $-49,00$ & $-23,33$ \\
\hline $\begin{array}{l}\text { Средний уровень } \\
\text { ресурсной зависимости }\end{array}$ & $-5,30$ & 7,73 & $-0,81$ & 0,09 & 2,26 & 4,16 & 2,55 & $-3,09$ & 1,27 \\
\hline $\begin{array}{l}\text { Низкий уровень ресурсной } \\
\text { зависимости }\end{array}$ & 6,53 & $-0,77$ & $-0,79$ & 5,92 & $-1,00$ & 6,36 & $-4,71$ & $-12,27$ & 11,64 \\
\hline Всего & $\mathbf{0 , 5 1}$ & $\mathbf{- 8 , 4 5}$ & $\mathbf{- 1 2 , 4 7}$ & $\mathbf{- 5 , 0 3}$ & $\mathbf{- 1 1 , 6 1}$ & $\mathbf{- 2 , 7}$ & $\mathbf{- 1 1 , 3 9}$ & $\mathbf{- 1 7 , 3 5}$ & $\mathbf{5 , 6}$ \\
\hline
\end{tabular}

Источник: Численность и миграция населения Российской Федерации, 2011-2019 гг. (2019) // Федеральная служба государственной статистики // https://rosstat.gov.ru/bgd/regl/b20_107/Main.htm, дата обращения 15.10.2021.

В таблице 1 представлены коэффициенты миграционного прироста/оттока (отношение миграционного прироста/оттока к среднегодовой численности постоянного населения территории), демонстрирующие интенсивность и результат 
миграции в расчете на 10 тыс. чел. по группам регионов за 2011-2019 гг. Очень высокий уровень ресурсной зависимости регионов связан со значительным уровнем миграционной убыли населения. Наивысшие показатели убыли в России с 2007 г. стабильно демонстрируют Магаданская область, ЯНАО (исключение 2011 г.), Республика Саха (Якутия); минимальные показатели убыли и в отдельные годы даже прирост - Ненецкий АО. В группе регионов с высоким уровнем ресурсной зависимости единственный регион - Томская область - имеет положительный показатель прироста, а Республика Коми многие годы показывает очень высокую убыль. В группе регионов со средним уровнем ресурсной зависимости очень высокие показатели миграционной убыли наблюдаются в географически крайних регионах страны - Мурманской области и Камчатском крае. Республики Карелия, Удмуртия, Хакасия и Пермский край обнаруживают средний или слабый уровень миграционной убыли. Республика Татарстан, Белгородская область находятся в благополучной зоне прироста. В группе из 17 российских регионов с положительным миграционным приростом в 2018 г. оказались три региона со средним уровнем ресурсной зависимости (Республика Татарстан, Белгородская область и Тюменская область (без автономных округов)) и один - Чукотский автономный округ с очень высоким (что представляется неожиданным, поскольку до 2017 г. он являлся одним из лидеров по миграционной убыли). В перечне регионов ресурсного типа с миграционным приростом находятся регионы, характеризующиеся развитыми региональными системами высшего образования, регионы же с миграционной убылью имеют более слабые системы. Фактически вузовская сеть стала дорогой с односторонним движением, формирующей исходящие потоки человеческого капитала из регионов ресурсного типа.

Ресурсозависимые регионы характеризуются меньшим количеством студентов как в общей численности населения, так и в численности населения студенческих возрастов (17-21 год). Исключение составляет группа из шести регионов с высоким уровнем ресурсной зависимости (группа 3), которая по этим показателям весьма близка к нересурсным регионам (в основном за счет Томской области, см. таблииу 2). При этом по сравнению с 2011/2012 учебным годом доля учащихся в населении студенческих возрастов в регионах с низким уровнем ресурсной зависимости сократилась на 11,6 п. П. (с 64,9 до 53,3\%), в регионах ресурсного типа на 17,4 п. п. (с 61,2 до 43,8\%).

Востребованность вузов регионов, определяемая на основе сравнения потока выпускников школ и студентов, зачисленных на 1-й курс очной формы обучения ${ }^{5}$ [Габдрахманов, Никифорова, Лешуков 2019, с. 16], также показывает худшее положение регионов ресурсного типа: по данным 2017 г. - 0,73 (снижается) по сравнению с 0,9 (стабильна). Лишь в трех регионах ресурсного типа (Томская и Самарская области, Республика Татарстан) данный показатель выше 1. В Томской области размещены два НИУ и один опорный университет, в Самарской - один НИУ и один опорный университет, в Республике Татарстан - Федеральный университет и два НИУ; эти же регионы характеризуются миграционным приростом.

\footnotetext{
5 Отношение численности поступивших на очную форму обучения по программам бакалавриата и специалитета в вузы региона сразу после окончания школы к численности выпускников школ региона, получивших аттестат о среднем общем образовании, скорректированной на долю выпускников школ, которые идут после окончания школы сразу в вузы.
} 
Таблица 2. Некоторые характеристики численности студентов регионов различного уровня ресурсной зависимости за 2019/2020 уч. год

\begin{tabular}{|l|c|c|c|c|}
\hline & \multicolumn{2}{|c|}{$\begin{array}{c}\text { Численность студентов } \\
\text { на 10 тыс. населения }\end{array}$} & \multicolumn{2}{|c|}{$\begin{array}{c}\text { Доля студентов в населении } \\
\text { «стуенческих возрастов }\end{array}$} \\
\cline { 2 - 5 } & $\mathbf{2 0 1 8 / 2 0 1 9}$ & $\mathbf{2 0 1 9 / 2 0 2 0}$ & $\mathbf{2 0 1 8 / 2 0 1 9}$ & $\mathbf{2 0 1 9 / 2 0 2 0}$ \\
\hline $\begin{array}{l}\text { Очень высокий уровень ресурсной } \\
\text { зависимости }\end{array}$ & 130,00 & 122,33 & 26,67 & 23,72 \\
\hline $\begin{array}{l}\text { Преобладание добывающих отраслей } \\
\text { над обрабатывающими при средней доле } \\
\text { добывающих отраслей в ВРП }\end{array}$ & 213,00 & 211,67 & 41,68 & 40,9 \\
\hline Высокий уровень ресурсной зависимости & 275,33 & 266,33 & 55,23 & 51,46 \\
\hline Средний уровень ресурсной зависимости & 248,00 & 238,73 & 54,94 & 51,4 \\
\hline Низкий уровень ресурсной зависимости & 249,14 & 246,05 & 55,1 & 53,3 \\
\hline
\end{tabular}

Источники: Регионы России. Социально-экономические показатели - 2019 г. (2019) // Федеральная служба государственной статистики // https://gks.ru/bgd/regl/B19_14p/Main.htm; Численность населения Российской Федерации по полу и возрасту на 1 января 2019 (2019) // Федеральная служба государственной статистики // https://www.gks.ru/bgd/regl/b19_111/Main.htm; Численность населения Российской Федерации по полу и возрасту на 1 января 2020 (2020) // Федеральная служба государственной статистики // https://www.gks.ru/bgd/regl/b20_111/Main.htm, дата обращения 15.10.2021.

Таким образом, сформированная региональная сеть вузов и институциональный дизайн образовательной системы формируют отток человеческого капитала из регионов ресурсного типа. Кроме того, в этих регионах системы высшего образования (за редким исключением) оказываются в относительно худшем положении как по базированию статусных вузов, так и по динамике численности студентов [Курбатова и др. 2021]. В результате регионы несут серьезные потери, превращаясь в поставщиков не только природных и финансовых ресурсов, но и человеческого капитала. С такими потерями сталкивается Кемеровская область, численность населения которой сократилась с начала 2003 г. на 260 тыс. чел., или почти на $10 \%$.

Кузбасс относится к регионам с высокой степенью ресурсной зависимости. Ведущей добывающей отраслью является угольная, цепочки производства стоимости короткие, экологическая ситуация неблагоприятная. Экономика области, состояние регионального рынка труда и регионального бюджета зависят от конъюнктуры рынка угля. Область высокоурбанизированная (86\% городского населения), является лидером в Российской Федерации по количеству монопрофильных муниципальных образований (в области 24 моногорода, в которых проживает $63 \%$ всего населения ${ }^{7}$ ). Региональная система высшего образования явно уступает ближайшим соседям: в соседних регионах расположены Федеральный университет

\footnotetext{
6 Численность населения Кемеровской области - Кузбасса на начало года (2021) // Территориальный орган Федеральной службы государственной статистики по Кемеровской области - Кузбассу // https://kemerovostat.gks.ru/storage/mediabank/hfZN3dry/Численность населения Кемеровской области - Кузбасса на начало года.pdf, дата обращения 15.10.2021.

7 Моногорода // Департамент инвестиционной политики и развития предпринимательства Кузбасса // http://dep.keminvest.ru/menu/deyatelnost/mono_sity.php, дата обращения 15.10.2021.
} 
(Красноярский край), три НИУ (два - в Томской и один - в Новосибирской областях), четыре опорных университета (по одному в Новосибирской и Томской областях, Алтайском и Красноярском краях). Основные показатели развития высшего образования Кузбасса ниже не только средних показателей регионов РФ, но и средних показателей регионов ресурсного типа и даже регионов с высоким уровнем ресурсной зависимости, к которой принадлежит область (таблица 3). В Кузбассе базируется один опорный университет, по уровню обеспеченности учебными местами региональная система высшего образования занимает 59-61-е место, по качеству образования - 37-е [Громов и др. 2016, с. 11-12].

\section{Таблица 3. Характеристики региональной системы высшего образования}

\begin{tabular}{|c|c|c|c|c|}
\hline Показатель & Кузбасс & $\begin{array}{l}\text { Высокий уровень } \\
\text { ресурсной } \\
\text { зависимости } \\
\text { (6 регионов) }\end{array}$ & $\begin{array}{c}\text { Регионы } \\
\text { ресурсного } \\
\text { типа } \\
\text { (26 регионов) }\end{array}$ & $\begin{array}{c}\text { Bсе } \\
\text { регионы }\end{array}$ \\
\hline $\begin{array}{l}\text { Численность студентов на } 10 \text { тыс. чел., } \\
\text { 2019/2020 учебный год, чел. }\end{array}$ & 176 & $\begin{array}{c}266,3 \\
(\text { Томская } \\
\text { область }-533)\end{array}$ & 215,1 & 236,2 \\
\hline $\begin{array}{l}\text { Доля студентов в населении «студенческих» } \\
\text { возрастов, 2019/2020 учебный год, \% }\end{array}$ & 37,9 & $\begin{array}{c}51,5 \\
\text { (Томская } \\
\text { область - 98,5) }\end{array}$ & 43,8 & 50,3 \\
\hline $\begin{array}{l}\text { Изменение численности профессорско- } \\
\text { преподавательского состава } \\
\text { (отношение численности ППС в } 2020 \text { г. } \\
\text { к численности в } 2013 \text { г.), \% }\end{array}$ & 47,6 & $\begin{array}{c}59,3 \\
(\text { Томская } \\
\text { область }-65,5)\end{array}$ & 61,7 & 64,1 \\
\hline $\begin{array}{l}\text { Коэффициент востребованности вузов } \\
\text { выпускниками школ, } 2017 \text { г. }\end{array}$ & 0,67 & $\begin{array}{c}0,87 \\
\text { (Томская } \\
\text { область }-1,89)\end{array}$ & 0,77 & 0,9 \\
\hline $\begin{array}{l}\text { Коэффициент миграционного прироста } \\
\text { на } 1000 \text { чел., } 2019 \text { г. }\end{array}$ & $-0,9$ & $\begin{array}{c}-2,33 \\
(\text { Томская } \\
\text { область }-3,0)\end{array}$ & $-0,36$ & 0,56 \\
\hline
\end{tabular}

Источники: [Габдрахманов, Никифоров, Лешуков 2019]; Численность и миграция населения Российской Федерации в 2018 г. // Федеральная служба государственной статистики // https://rosstat.gov.ru/bgd/regl/b19_107/Main.htm, дата обращения 15.10.2021.

На образовательную миграцию в Кузбассе воздействуют различные факторы. Во-первых, это неудовлетворительное состояние региональной экономики и рынка труда: объем и качество рабочих мест все меньше отвечают растущим требованиям выпускников школ качества жизни РБК за 2020 г.9); в-третьих - характеристики региональной обра-

8 Потапова Ю. (2018) Профориентация на выезд. Почему выпускники школ и вузов все чаще покидают Кузбасс? // Российская газета. 20 декабря 2018 // https://rg.ru/2018/12/20/reg-sibfo/pochemu-vypusknikishkol-i-vuzov-vse-chashche-pokidaiut-kuzbass.html; Потапова Ю. (2020) Здесь климат иной... Почему молодежь и мобильные люди активного возраста уезжают из Сибири // Российская газета. 27 февраля 2020 // https://rg.ru/2020/02/27/reg-sibfo/pochemu-molodezh-uezzhaet-iz-sibiri.html, дата обращения 15.10.2021.

9 Лучшие регионы для жизни (2021) // https://www.rbc.ru/economics/26/04/2021/6078136e9a7947d0e9e1b1fb, дата обращения 15.10.2021. 
зовательной системы, которая ввиду своих более слабых позиций «выталкивают» выпускников школ из региона.

Начиная с 2011 г. в Кузбассе наблюдается отрицательное сальдо общей миграции, при этом до 2014 г. включительно сальдо образовательной миграции также было отрицательным и примерно повторяло масштабы общей миграционной убыли (рисунок 1). В 2015 г. перевес выбытия на учебу над прибытием в связи с учебой оказался минимальным, а в 2016 г. соотношение стало обратным. 2018 год ознаменовался самым высоким за 10 лет миграционным оттоком и одновременно превышением въезда в связи с учебой над выбытием по той же причине (на 918 чел.). Доля образовательных мигрантов в общей численности прибывших в регион достигла 24\%, удвоившись по сравнению с 2011 г;; доля в общей численности выбывших за 10 лет выросла с 8,2 до 20,3\%, причем основной рост (до 17,3\%) произошел в 2011 г., что стало следствием введения ЕГЭ.

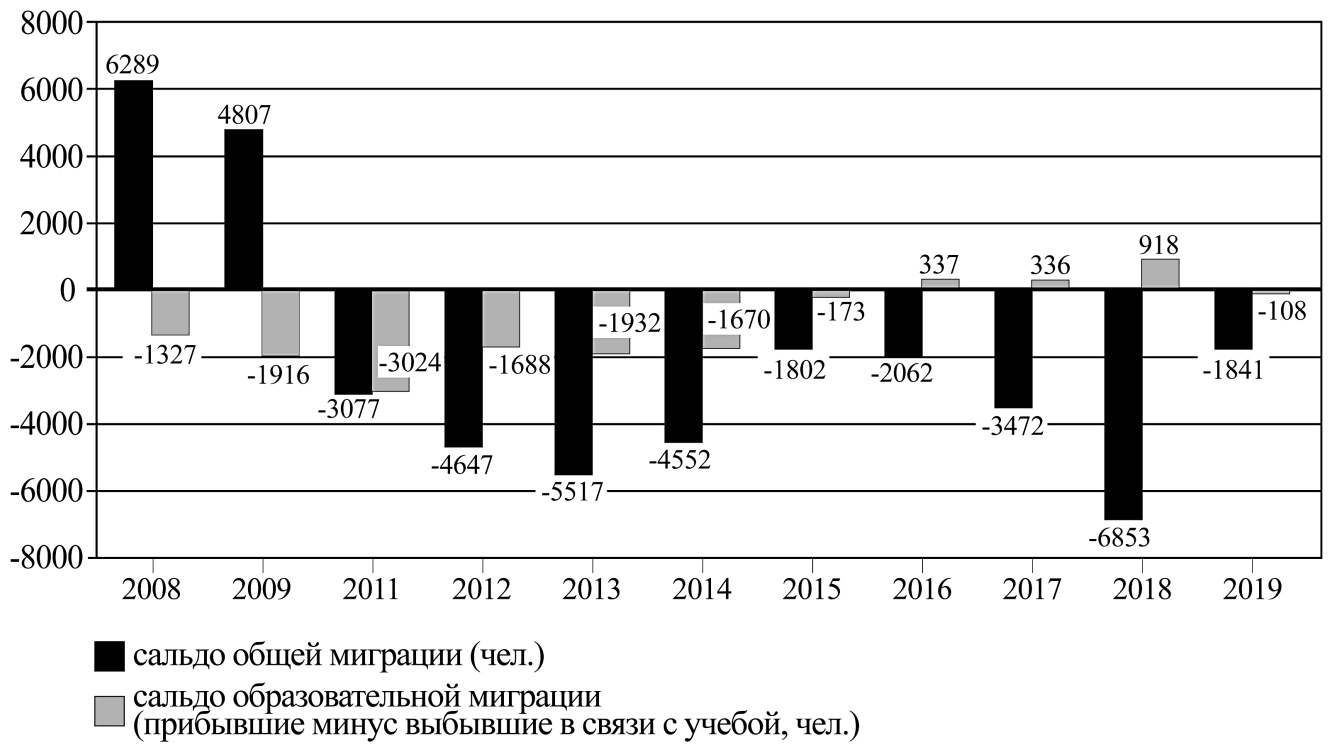

Рисунок 1. Динамика общей и образовательной миграции в Кемеровской области - Кузбассе

Источник: Территориальный орган Федеральной службы государственной статистики по Кемеровской области - Кузбассу

Доля международных мигрантов (из стран СНГ) в общей численности прибывших в связи с учебой выросла с 0,9\% в 2011 г. до 11,9\% в 2018 г., а в 2019 г. достигла рекордного уровня - 41\%. Это совпадает с ведением в 2013 г. мониторинга эффективности вузов и включением в его состав показателей, характеризующих долю иностранных студентов: почти каждый третий международный мигрант приезжает в Кемеровскую область учиться. С 2017 г. въездная 
образовательная миграция в регионе становится отчетливо более «внешней» по сравнению с общей иммиграцией. Общее положительное сальдо образовательной миграции формируется главным образом за счет студентов из стран СНГ (прежде всего из Казахстана и Таджикистана), а сальдо внутрироссийских образовательных миграций для Кемеровской области складывается резко не в ее пользу. Интенсификация потоков образовательной миграции в Кузбассе сопровождается и качественными сдвигами: поток образовательных эмигрантов из области характеризуется более высокими баллами ЕГЭ по сравнению с приезжающими [Урбан 2019]. В результате Кузбасс не получает отдачи на сделанные на уровне довузовского образования инвестиции в человеческий капитал и становится его поставщиком.

Пример Кемеровской области подтверждает влияние таких структурных факторов формирования потоков образовательной миграции, как новации в управлении высшим образованием, состояние региональной системы высшего образования и ресурсно-отраслевые характеристики региона, и в дальнейшем указанные факторы структурируют соответствующие решения домохозяйств.

\section{Принятие решения домохозяйствами об образовательной миграции: кейс одного класса}

Важнейшей частью инвестиций Кузбасса, как и других регионов, в человеческий капитал является создание образцовых общеобразовательных учреждений, которые одновременно выполняют функции обучения детей региональной элиты, высокообразованных групп населения и «витрины» образовательной системы, демонстрирующей эффективность управления региональными образовательными системами. Однако данные затраты не просто не ведут к накоплению человеческого капитала, но и формируют каналы его оттока. Так, выпускники двух губернаторских учебных заведений - Губернаторской женской гимназии-интерната и Губернаторского многопрофильного лицея-интерната - предпочитают выезд на обучение в другие регионы. В 2017 г. среди выпускников, поступивших в вузы, доля выбывших в другие регионы составила $38,2 \%$, в 2018 г. - 49,2\%, в 2019 г. $52,8 \%$, в 2020 г. - 58,3\%. Наблюдается возрастающий отток стобалльников ЕГЭ, победителей и призеров заключительного этапа Всероссийской олимпиады школьников (рисунок 2).

Показатели высокого оттока хорошо подготовленных учеников иллюстрирует кейс класса одного из лицеев г. Кемерово, почти все выпускники которого уехали учиться в вузы за пределами региона (два выпускника сразу после школы остались в Кемерово для обучения в университете, чтобы получить разрешение на продолжение учебы за границей через год). Класс специализировался по STEMспециальностям, выпускники для обучения в университете в основном выбирали направления, связанные с информационными технологиями, физикой, инженерией. Отток выпускников распределился по традиционным направлениям: Томск (2 чел.), Новосибирск (7 чел.), Москва (3 чел.) и Санкт-Петербург (9 чел.).

Для изучения выбора домохозяйств при принятии решений об образовательной миграции было проведено интервью с родителями выпускников класса. 
Выборка была сплошной, из 23 семей выпускников мы получили интервью у 18 семей. Следует отметить, что договоренность об интервью была с семьей в целом, но в 17 интервью принимали участие только матери (отцы либо проживали отдельно, либо отсутствовали в момент интервью). Структура гайда интервью состояла из следующих блоков: общая информация о выпускнике (университет, в котором обучается; условия поступления и обучения); выбор профессии (когда и кем осуществлялся, что и кто на него влиял); приоритеты выбора (на что был ориентир в выборе: профессия, университет, город или др.); оценка региональных условий для продолжения образования (причины притяжения/«выталкивания»); субъективная оценка выбора (удовлетворенность принятым решением, перспективы возвращения в регион после продолжения образования).

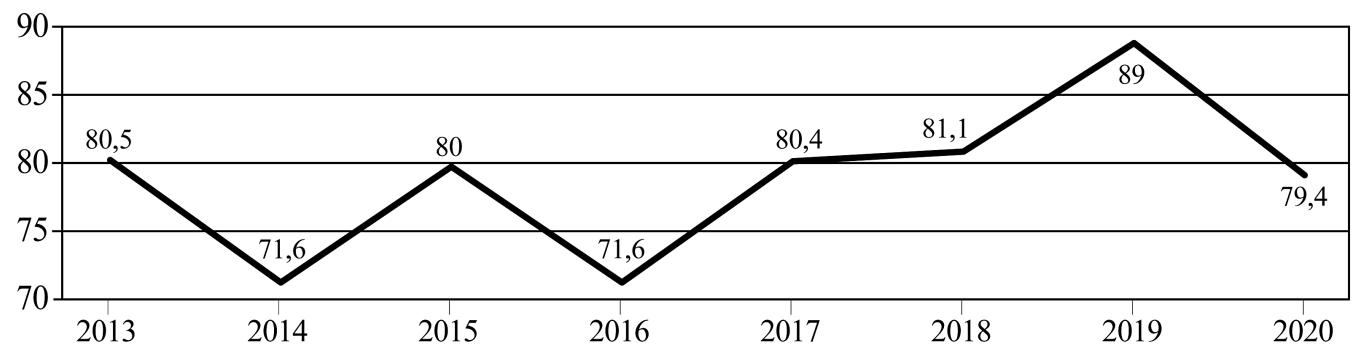

Рисунок 2. Доля выпускников-стобалльников, победителей и призеров заключительного этапа Всероссийской олимпиады школьников, выбывших на обучение за пределы Кемеровской области - Кузбасса, \%

Полученные данные свидетельствуют о том, что переход «школа - вуз» рассматривается как «судьбоносный момент» для всего домохозяйства. Решение об образовательной миграции принимается семьями задолго до выпускного класса: «Задумались о профессии давно, много с сыном говорили. Когда в лицей пошли, сразу знали, что ребенок уедет. Не знали еще тогда точно, в какой город, университет»; "С выбором профессии начали определяться с 9 класса. Ездили на дни открытых дверей выбранных вузов». Можно говорить о том, что выбор образовательного учреждения в старших классах уже является частью стратегии образовательной мобильности: родители переводят детей в школы, лицеи, гимназии, выпускники которых получают высокие баллы и поступают в лучшие учебные заведения страны.

Родители замечают, что в выборе направления подготовки ориентировались в основном на желание и интерес школьника («интерес, способности $\kappa$ информатике и математике»), дальнейшие перспективы («на способности, наклонности ребенка и актуальность профессии в современном обществе»; «востребованность профессии, возможности дальнеймего трудоустрой(ттва»). На вопрос о том, что же стало решающим в выборе, мы получали как ответы личностного характера («..внутренний голос ребенка; он сказал, что 
почувствовал, что именно это его»), так и ответы, основанные на семейных факторах («поддержка семьи, конечно; мы поможем в период учебы материально и морально, сами были студентами, знаем, как это»; «мы ориентируемся на продолжение семейного бизнеса; вот окончит университет, получит хорошие новые знания, будет двигать наше дело»). Решение об образовательной миграции принималось семьями уже в среднем звене школьного цикла, совместно с учетом интересов ребенка и дальнейших планов семьи, иногда с решающим голосом родителей («выбор пришлось делать маме, потому что ребенок затруднялся с выбором факультета»; "решающий голос принадлежал ребенку, но мы как родители были согласны с его выбором»).

При выборе вуза первоочередным оказался выбор города: его возможностей («прекрасный европейский культурный город, отличный вуз, наличие перспектив и возможностей», "по его профессии выбор университетов небольшой; поступил в Томск и Москву; решили в Москву, потом интереснее варианть с трудоустройством будут»); расположения («город рядом с Кемерово; университет - из-за специиальности, таких факультетов три в России», "не хотела, чтобы ребенок далеко уезжал, я боялась, что скучать буду; а Новосибирск - город больше, интереснее, по сравнению с Томском»). Была отмечена и важность статуса университета («выбирали направление и университет; имели значение статус и рейтинг вуза»). Выбор конкретного города и университета также был сопряжен с семейными обстоятельствами («родственники там живут, если что, поддержат во время учебы, да и потом с работой помогут»; "Питер мне нравится, красивый город, университеты хорошие; у меня ещуе один ребенок - школьник, после окончания им школь мы всей семьей туда перебираться будем»). Заметим, что модель переезда семьи с окончанием ребенком школы становится все более распространенной в регионе, и образовательная миграция выпускника оказывается сопряженной с мобильностью членов его семьи. Это усиливает отток человеческого капитала из региона, который проявляется не только в потенциальных, но и в реальных потерях квалифицированных специалистов.

Решение покинуть регион для получения образования родители выпускников объясняют негативными региональными тенденциями ("отсутствие перспективы, слабая сочиальная сфера, плохая экология»; «упадок производства в регионе») и сложностями трудоустройства («думаю, в дальнейшем трудно будет найти работу по специчальности»; "знаете, у нас зарплатьл низкие, самому искать работу сложно»; "отталкивает отсутствие рабочих мест с достойной зарплатой»). Возвращение в регион после окончания обучения родителями воспринимается как нежелательный итог («возможно, но это не лучший результат»; «нет, но все может быть; желаю дальнейшего развития своему ребенку»).

Результаты интервью позволяют говорить о том, что образовательная миграция при переходе «школа - вуз» для выпускников образцового образовательного учреждения, имеющего особую региональную поддержку, является семейным решением не только потому, что опирается на личные предпочтения, интеллектуальные возможности ребенка и ресурсы семей, но и потому, что основывается на долгосрочных семейных планах, связанных с мобильностью (территориальной, профессиональной) членов семьи. В таких условиях основными ориентирами 
становится поиск новых перспективных и статусных вариантов (города, университета), «выталкивающим» фактором оказывается неблагоприятная региональная ситуация (узкий рынок труда, экология, отсутствие перспектив). В целом это согласуется с выводами, сделанными в других исследованиях о том, что ведущие вузы выбираются преимущественно домохозяйствами с более высоким социально-экономическим положением, а регионы с меньшими государственными инвестициями в высшее образование сталкиваются со значительным чистым оттоком человеческого капитала.

\section{Выводы}

Как показало проведенное исследование, образовательная миграция при переходе «школа - вуз» определяется группой структурных факторов. Прежде всего, значение имеют ресурсно-отраслевые характеристики регионов. Регионы ресурсного типа характеризуются существенным миграционным оттоком населения, драйвером которого становится образовательная миграция как важнейший элемент миграционных стратегий домохозяйств. Эти регионы становятся поставщиками не только природных и финансовых ресурсов, но и человеческого капитала. Наблюдается «западный дрейф» образовательной миграции, усиливающий общий миграционный поток в западном направлении.

Формирование потоков образовательной миграции во многом определяется сложившимся институциональным дизайном системы высшего образования (механизмами отбора абитуриентов, характером развития сети вузов, отдельными показателями мониторинга эффективности деятельности вузов и т. п.). «Институциональный принцип» организации системы высшего образования, при котором объектом управления оказывается образовательная организация, ведет к тому, что при определении приоритетов образовательной политики практически не учитываются последствия ее реализации для регионального развития. Инвестиции регионов в человеческий капитал на уровне среднего образования, не дополненные соответствующими федеральными инвестициями на уровне высшего образования, способствуют утечке человеческого капитала в результате образовательной миграции. Согласно нашему исследованию, от новаций образовательной политики России больше всего пострадало высшее образование регионов ресурсного типа (за редким исключением), прежде всего в области доступности качественного образования. Сформированная сеть вузов и распределение контрольных цифр приема определили отток человеческого капитала из этих регионов.

Отдельно следует отметить формирование новых миграционных стратегий домохозяйств. Переход «школа - вуз» рассматривается как «судьбоносный момент», к которому готовятся заранее, а окончание школы одним из детей становится импульсом для миграции всей семьи (одновременной или растянутой во времени). В регионах ресурсного типа данные процессы могут протекать более интенсивно вследствие узости и специфики рынков труда, экологических проблем, качества среды проживания и т. п., причем отток осуществляют домохозяйства, занимающие более высокое социально-экономическое положение, и, как следствие, 
регионы теряют не только потенциальных специалистов, но и действующих высококвалифицированных работников и предпринимателей.

Таким образом, наблюдаемые процессы образовательной миграции при переходе «школа - вуз» и их возможные долговременные последствия, связанные с формированием кумулятивной связи образовательной миграции и регионального развития, требуют изменений в проводимой социальной-экономической политике. Прежде всего, на региональном уровне приоритетными должны стать задачи развития рынков труда и создания привлекательных для молодежи рабочих мест; требуются и пересмотр подходов к образовательной политике как на федеральном, так и на региональных уровнях, отказ от однобоких отраслевых подходов к определению эффективности функционирования российской системы высшего образования.

\section{Список источников}

Бессуднов А.Р., Куракин Д.Ю., Малик В.М. (2017) Как возник и что скрывает миф о всеобщем высшем образовании // Вопросы образования. № 3. С. 83-109.

Варшавская Е.Я., Чудиновских О.С. (2014) Миграционные планы выпускников региональных вузов России // Вестник Московского университета. Серия 6: Экономика. № 3. С. 36-58.

Габдрахманов Н.К. (2019) Концентрация студентов в системе высшего образования на карте Российской Федерации // Вестник Российского университета дружбы народов. Серия: Экономика. Т. 27. № 1. С. 7-17.

Габдрахманов Н.К., Лешуков О.В., Платонова Д.П. (2019) Обеспеченность бюджетными местами региональных систем высшего образования с учетом демографических трендов // Университетское управление: практика и анализ. № 4. С. 32-45.

Габдрахманов Н.К., Никифорова Н.Ю., Лешуков О.В. (2019) «От Волги до Енисея...»: образовательная миграция молодежи в России. М.: ВШЭ.

Громов А.Д., Платонова Д.П., Семенов Д.С., Пырова Т.Л. (2016) Доступность высшего образования в регионах России. М.: ВШЭ.

Захаров А.Б., Адамович К.А. (2020) Региональные различия в доступе к образовательным ресурсам, в академических результатах и в траекториях российских учащихся // Экономическая социология. Т. 21. № 1. С. 60-80.

Кашницкий И.С., Мкртчян Н.В., Лешуков О.В. (2016) Межрегиональная миграция молодежи в России: комплексный анализ демографической статистики // Вопросы образования. № 3. С. 169-203.

Козлов Д.В., Платонова Д.П., Лешуков О.В. (2017) Где учиться и где работать: межрегиональная мобильность студентов и выпускников университетов. М.: ВШЭ.

Коновалов А.Б., Блинов А.В., Ермолаев А.Н., Карпинец А.Ю. (2019) Кемеровский государственный университет: очерки предыстории и становления в советский период (1949-1991): монография. Кемерово: Кемеровский государственный университет.

Константиновский Д.Л., Попова Е.С. (2015) Молодежь, рынок труда и экспансия высшего образования // Социологические исследования. № 11. С. 3-48.

Кузьминов Я.И., Семенов Д.С., Фрумин И.Д. (2013) Структура вузовской сети: от советского к российскому «мастер-плану» // Вопросы образования. № 4. С. 8-69.

Курбатова М.В., Донова И.В., Кранзеева Е.А. (2021) Высшее образование в регионах ресурсного типа: между задачами ведомственного и регионального // Terra Economicus. T. 19. № 1. C. 109-123. DOI: 10.18522/2073-6606-2021-19-1-109-123

Курбатова М.В., Левин С.Н., Каган Е.С., Кислицын Д.В. (2019) Регионы ресурсного типа в России: определение и классификация // Terra Economicus. T. 17. № 3. С. 89-106. 
Курбатова М.В., Левин С.Н., Саблин К.С. (2020) «Утроенный провал» институционального проектирования в реформировании высшего образования России // Journal of Institutional Studies (Журнал институциональных исследований). Т. 12. № 4. C. 94-111.

Лешуков О.В., Лисюткин М.А. (2015) Управление региональными системами высшего образования в России: возможные подходы // Университетское управление: практика и анализ. № 6(100). С. 29-40.

Лисюткин М.А. (2017) О возможных причинах ухудшения ресурсной базы вузов // Вопросы образования. № 2. С. 74-94.

Лисюткин М.А., Фрумин И.Д. (2014) Как деградируют университеты? К постановке проблемы // Университетское управление: практика и анализ. № 4-5 (92-93). С. 12-20.

Мкртчян Н.В. (2014) О влиянии миграции на возрастной состав населения регионов, городов и районов России // Коровкин А.Г. (ред.) Научные труды: ИНП РАН. М.: МАКС Пресс. С. 381-396.

Урбан О.А. (2019) Социальные практики набора в российских вузах // Мир России. Т. 28. № 2. C. 125-147.

Хавенсон Т.Е., Чиркина Т.А. (2018) Эффективно поддерживаемое неравенство. Выбор образовательной траектории после 11-го класса школы в России // Экономическая социология. Т. 19. № 5. С. 66-89.

Черныш М.Ф., Епихина Ю.Б. (ред.) (2018) Многомерная социальная мобильность в современной России: монография. М.: Институт социологии ФНИСЦ РАН.

Шагалкина М.В., Латуха М.О., Мицкевич Е.А., Строгецкая Е.В. (2019) Факторы миграционных намерений талантливых выпускников ведущих вузов России // Российский журнал менеджмента. Т. 17. № 4. С. 445-466.

Abel J.R., Deitz R. (2011) Do Colleges and Universities Increase Their Region's Human Capital? // Journal of Economic Geography, vol. 12, no 3, pp. 667-691.

Christie H. (2007) Higher Education and Spatial (Im)Mobility: Nontraditional Students and Living at Home // Environment and Planning A, vol. 39 no 10, pp. 2445-2463.

Ciriaci D. (2014) Does University Quality Influence the Interregional Mobility of Students and Graduates? // The Case of Italy, Regional Studies, vol. 48, no 10, pp. 1592-1608.

DiMaggio P. (1982) Cultural Capital and School Success: The Impact of Status Culture Participation on the Grades of U.S. High School Students // American Sociological Review, vol. 47, no 2, pp. 189-201.

Evans K. (2002) Taking Control of Their Lives? Agency in Young Adult Transitions in England and the New Germany // Journal of Youth Studies, vol. 5, no 3, pp. 245-269.

Faggian A. (2006) Human Capital Flows and Regional Knowledge Assets: A Simultaneous Equation Approach // Oxford Economic Papers, vol. 58, no 3, pp. 475-500.

Faggian A., McCann P. (2009) Universities, Agglomerations and Graduate Human Capital Mobility // Tijdschrift Voor Economische En Sociale Geografie, vol. 100, no 2, pp. 210-223.

Haapanen M., Tervo H. (2011) Migration of the Highly Educated: Evidence from Residence Spells of University Graduates // Journal of Regional Science, vol. 52, no 4, pp. 587-605.

Holland J., Thomson R. (2009) Gaining Perspective on Choice and Fate: Revisiting Critical Moments // European Societies, vol. 11, no 3, pp. 451-469.

Pakulski J., Waters M. (1996) The Death of Class, London: Sage.

Sjaastad L.A. (1962) The Costs and Returns of Human Migration // Journal of Political Economy, vol. 70, no 5, pp. 80-93. 


\title{
Educational Migration in Resource-Extracting Regions
}

\author{
M.V. KURBATOVA*, I.V. DONOVA**, E.A. KRANZEEVA***, \\ M.G. LEUKHOVA****
}

\begin{abstract}
*Margarita V. Kurbatova - DSc in Economics, Professor, Department of Social and Economic Planning, Siberian Federal University, Krasnoyarsk, Russian Federation, kurbatova-07@mail.ru, https://orcid.org/0000-0002-7017-5266

**Inna V. Donova - PhD in Economics, Associate Professor, The Povarich Department of Management, Kemerovo State University, Kemerovo, Russian Federation, idonova@gmail.com, https://orcid.org/ 0000-0001-9370-5402

***Elena A. Kranzeeva - PhD in Sociology, Head, Department of Social Sciences, Kemerovo State University, Kemerovo, Russian Federation, elkranzeeva@mail.ru, https://orcid.org/0000-0003-2577-9017

$* * *$ Maria G. Leukhova - PhD in History, Associate Professor, Department of Russian History, Kemerovo State University, Kemerovo, Russian Federation, leukhova@kemsu.ru, https://orcid.org/0000-0002-5891-2737
\end{abstract}

Citation: Kurbatova M.V., Donova I.V., Kranzeeva E.A., Leukhova M.G. (2022) Educational Migration in Resource-Extracting Regions. Mir Rossii, vol. 31, no 1, pp. 91-112 (in Russian). DOI: $10.17323 / 1811-038 \mathrm{X}-2022-31-1-91-112$

\begin{abstract}
This article focuses on educational migration as a result of the "school-university" transition in resource-extracting regions. We identify and characterize the structural and subjective factors of such migration. The most important structural factors include opportunities provided by the region, its economic structure, and the labor market. We argue that the flow of educational migration from resource-extracting regions is higher than the national average. This situation is accompanied by a "negative selection" of human capital, i.e., an outflow of graduates with higher educational achievement, usually associated with families with higher socioeconomic status. Resource-extracting regions become not just suppliers of natural and financial resources to the Russian economy, but also suppliers of human capital. Educational migration in Russia has a pronounced "western drift". An important structural factor in the formation of educational migration flows is the institutional design of the higher education system, which has emerged in Russia as a result of reforms aimed at increasing efficiency. Corresponding institutional innovations (the introduction of the Unified State Examination, new mechanisms for allocating admissions, and university performance evaluation) made university education less accessible in resource-extracting regions. Exceptions include only a few established university centers (Tomsk, Kazan, Samara). We also describe the new migration strategies adopted by households. The "school-university" transition is often considered a "fateful moment", for which families prepare in advance, and which sometimes involves the relocation of the entire family. Structural factors of educational migration are described in more detail using the case of the Kemerovo regionKuzbass. The article presents data on the outmigration of top-ranking pupils, enhanced with indepth interviews with the parents of graduates of one of the top secondary educational institutions of Kuzbass. They reveal that educational migration is a family decision not only because it relies
\end{abstract}

This research was supported by the Russian Foundation for Basic Research, grant № 19-010-00244 "Institutional setup of the labor market in resource-type regions”.

The article was published as part of the HSE University project "University Partnership", to support publications by authors of Russian educational and scientific organizations.

The article was received in June 2021. 
on personal preferences, children's abilities, and family resources, but also because it is based on long-term family plans associated with relocation. It is shown that such educational migration can have negative long-term consequences as a result of the feedback loop between educational migration and regional development. This prompts specific policy responses at both the federal and regional levels.

Keywords: educational migration, resource-extracting regions, resource-abundant regions, labor markets, higher education, regional development, household migration strategies

\section{References}

Abel J.R., Deitz R. (2011) Do Colleges and Universities Increase Their Region's Human Capital? Journal of Economic Geography, vol. 12, no 3, pp. 667-691.

Bessudnov A., Kurakin D., Malik V. (2017) The Myth about Universal Higher Education: Russia in the International Context. Voprosy obrazovaniya / Educational Studies Moscow, no 3, pp. 83-109 (in Russian).

Chernysh M.F., Epikhina Yu.B. (eds.) (2018) Multidimensional Social Mobility in Modern Russia, Moscow: FNISTS RAN (in Russian).

Christie H. (2007) Higher Education and Spatial (Im)Mobility: Nontraditional Students and Living at Home. Environment and Planning A, vol. 39 no 10, pp. 2445-2463.

Ciriaci D. (2014) Does University Quality Influence the Interregional Mobility of Students and Graduates? The Case of Italy, Regional Studies, vol. 48, no 10, pp. 1592-1608.

DiMaggio P. (1982) Cultural Capital and School Success: The Impact of Status Culture Participation on the Grades of U.S. High School Students. American Sociological Review, vol. 47, no 2, pp. 189-201.

Evans K. (2002) Taking Control of Their Lives? Agency in Young Adult Transitions in England and the New Germany. Journal of Youth Studies, vol. 5, no 3, pp. 245-269.

Faggian A. (2006) Human Capital Flows and Regional Knowledge Assets: A Simultaneous Equation Approach. Oxford Economic Papers, vol. 58, no 3, pp. 475-500.

Faggian A., McCann P. (2009) Universities, Agglomerations and Graduate Human Capital Mobility. Tijdschrift Voor Economische En Sociale Geografie, vol. 100, no 2, pp. 210-223.

Gabdrahmanov N.K. (2019) Concentration of Students in Higher Education on the Map of the Russian Federation. RUDN Journal of Economics, vol. 27, no 1, pp. 7-17 (in Russian).

Gabdrakhmanov N.K., Leshukov O.V., Platonova D.P. (2019) Accessibility of Regional Higher Education Systems in Accordance with Demographic Trends. University Management: Practice and Analysis, vol. 23, no 4, pp. 32-45 (in Russian).

Gabdrakhmanov N.K., Nikiforova N.Y., Leshukov O.V. (2019) “From Volga to Yenisei...”: Educational Migration of Youth in Russia, Moscow: HSE (in Russian).

Gromov A.D., Platonova D.P., Semenov D.S., Pyrova T.L. (2016) Accessibility of Higher Education in the Regions of Russia, Moscow: HSE (in Russian).

Haapanen M., Tervo H. (2011) Migration of the Highly Educated: Evidence from Residence Spells of University Graduates. Journal of Regional Science, vol. 52, no 4, pp. 587-605.

Holland J., Thomson R. (2009) Gaining Perspective on Choice and Fate: Revisiting Critical Moments. European Societies, vol. 11, no 3, pp. 451-469.

Kashnitsky I.S., Mkrtchyan N.V., Leshukov O.V. (2016) Interregional Migration of Youths in Russia: A Comprehensive Analysis of Demographic Statistics. Voprosy obrazovaniya / Educational Studies Moscow, no 3, pp. 169-203 (in Russian).

Khavenson T., Chirkina T. (2018) Effectively Maintained Inequality: The Choice of Postsecondary Educational Trajectory in Russia. Economic Sociology, vol. 19, no 5, pp. 66-89 (in Russian). 
Konovalov A.B., Blinov A.V., Ermolaev A.N., Karpinets A.Yu. (2019) Kemerovo State University: Essays of Background and Formation in the Soviet Period (1949-1991): Monograph, Kemerovo: Kemerovo State University (in Russian).

Konstantinovskiy D.L., Popova E.S. (2015) Youth, Labor Market and Expansion of Higher Education. Sociological Studies, no 11, pp. 37-48 (in Russian).

Kozlov D.V., Platonova D.P., Leshukov O.V. (2017) Where to Study and Where to Work: Interregional Mobility of University Students and Graduates, Moscow: HSE (in Russian).

Kurbatova M.V., Donova I.V., Kranzeeva E.A. (2021) Higher Education in the Resource-Type Regions: Between the Aims of Departmental and Regional Development. Terra Economicus, vol. 19, no 1, pp. 109-123 (in Russian). DOI: 10.18522/2073-6606-2021-19-1-109-123

Kurbatova M.V., Levin S.N., Kagan E.S., Kislitsyn D.V. (2019) Resource-type Regions in Russia: Definition and Classification. Terra Economicus, vol. 17, no 3, pp. 89-106 (in Russian).

Kurbatova M.V., Levin S.N., Sablin K.S. (2020) The "Tripled Failure" of Institutional Design of Higher Education Reform in Russia. Journal of Institutional Studies, vol. 12, no 4, pp. 94-111 (in Russian).

Kuzminov Y., Semyonov D., Froumin I. (2013) University Network Structure: From the Soviet to the Russian "Master Plan". Voprosy obrazovaniya / Educational Studies Moscow, no 4, pp. 8-69 (in Russian).

Leshukov O.V., Lisyutkin M.A. (2015) Governance of the Regional Higher Education Systems in Russia: Possible Approaches. University Management: Practice and Analysis, no 6(100), pp. 29-40 (in Russian).

Lisyutkin M. (2017) On Possible Reasons for University Resource Base Decline. Voprosy obrazovaniya / Educational Studies Moscow, no 2, pp. 74-94 (in Russian).

Lisyutkin M.A., Frumin I.D. (2014) How Do Universities Decline? The Problem Statement. University Management: Practice and Analysis, no 4-5 (92-93), pp. 12-20 (in Russian).

Mkrtchyan N.V. (2014) The Effect of Migration on the Age Structure of the Population of the Regions, Cities and Districts of Russia. Scientific Articles - Institute of Economic Forecasting Russian Academy of Sciences (ed. Korovkin A.G.), Moscow: MAKS Press, pp. 381-396 (in Russian).

Pakulski J., Waters M. (1996) The Death of Class, London: Sage.

Shagalkina M.V., Latukha M.O., Mitskevich E.A., Strogetskaya E.V. (2019) Factors of Migration Intentions of Talented Graduates from Leading Russian Universities. Russian Management Journal, vol. 17, no 4, pp. 445-466 (in Russian).

Sjaastad L.A. (1962) The Costs and Returns of Human Migration. Journal of Political Economy, vol. 70, no 5, pp. 80-93.

Urban O.A. (2019) Social Practices of Maintaining Enrollment at Russian Universities. Mir Rossii, vol. 28, no 2, pp. 125-147 (in Russian).

Varshavskaya E.Ya., Chudinovskikh O.S. (2014) Migration Intentions of Graduates of Russia's Regional Higher Educational Institutions. Moscow University Economics Bulletin, Series 6: Economy, no 3, pp. 36-58 (in Russian).

Zakharov A., Adamovich K. (2020) Regional Differences in Access to Educational Resources, Academic Results and Students' Trajectories in Russia. Economic Sociology, vol. 21, no 1, pp. 60-80 (in Russian). 